\title{
Presenting risk information in sexual and reproductive health care
}

\author{
Anna L David, ${ }^{1}$ Hannat Akintomide ${ }^{2}$
}

\begin{abstract}
${ }^{1}$ Reader and Consultant in Obstetrics and Maternal Fetal Medicine, Institute for Women's Health, University College London, London, UK ${ }^{2}$ Specialty Doctor in Sexual and Reproductive Health, CNWL Camden Provider ServicesSexual and Reproductive Health, Margaret Pyke Centre, London, UK
\end{abstract}

\section{Correspondence to}

Dr Anna L David, Institute for Women's Health, 86-96 Chenies Mews, London WC1E 6HX, UK; a.david@ucl.ac.uk

Received 24 January 2015 Revised 5 March 2016 Accepted 3 May 2016 Published Online First 6 June 2016

\section{CrossMark}

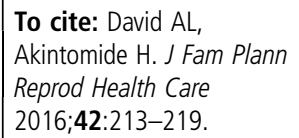

\begin{abstract}
Objectives Presenting risk information to patients is an important part of clinical encounters. Good risk communication improves patient satisfaction with their care and the decisions they make. In sexual and reproductive healthcare $(\mathrm{SRH})$, women frequently need to make decisions based on their perceived risk. Risk perception can be altered by how actual risk is presented to patients.
\end{abstract}

Methods Databases were searched using MeSH terms combined with a keyword search for articles relevant to $\mathrm{SRH}$; the search was limited to English language.

Results Personalised risk communication where a risk score is provided, increases knowledge and slightly increases uptake of screening tests.

Decision aids improve a patient's knowledge of the options, create realistic expectations of their benefits and harms, reduce difficulty with decision-making, and increase participation in the process. The most effective way to present risks uses a range of structured, tailored presentation styles; interactive formats are best. Framing the information improves patient understanding. Most people understand natural frequencies or event rates better than probability formats with varying denominators. Expressing changes in risk as an absolute risk reduction or relative risk reduction with baseline risk formats improves understanding. Descriptive terms such as 'low risk' or 'high risk' should be quantified as a frequency rather than a percentage. Using a consistent denominator to portray risk is recommended. Using the 'number needed to treat' and visual aids puts benefits or risks into perspective. The duration of risk should be presented.

Conclusion Presenting risk information to patients can be optimised using a number of strategies.

\section{INTRODUCTION}

Healthcare professionals often need to discuss risks with patients in sexual and reproductive healthcare (SRH). One

\section{Key message points}

- Presenting risk information to patients is an important part of clinical encounters and good risk communication improves patient satisfaction with their care.

- Strategies to improve patient understanding of risks include providing personalised risks, using decision aids, and presenting information in a variety of structured, tailored and/or interactive formats.

- To quantify risk, use numbers rather than words, event rates or natural frequencies rather than probabilities or relative risk reduction, and absolute risks rather than relative risks.

suggested approach involves first describing the frequency of the risk and then the possible associated harm. ${ }^{1}$ For instance, the risk of perforation during insertion of an intrauterine device (IUD) is $0-2.3$ per 1000 insertions, which is rare to uncommon, but this must be qualified by the amount of associated harm such as bowel perforation and peritonitis. Both healthcare professionals and patients have difficulty understanding risk in terms of numerical odds and probabilities. ${ }^{2}$ The Royal College of Obstetricians and Gynaecologists' Clinical Governance Advice on Presenting Information on Risk provides general principles on how best to communicate risk in women's health. ${ }^{3}$ In this paper we discuss how best to define and present descriptions of risk in clinical decision-making with patients in $\mathrm{SRH}$, using examples relevant to SRH.

\section{METHODOLOGY}

We searched the Cochrane Library [Cochrane Central Register of Controlled 
Trials (CENTRAL), HTA and the National Research Register], Cochrane Database of Systematic Reviews, the Centre for Reviews and Dissemination, the Database of Abstracts of Reviews of Effects (DARE), MEDLINE (Ovid), Excerpta Medica Database (Embase), Turning Research Into Practice (TRIP) database, National Electronic Library of Health and MEDLINE for relevant studies and articles published between 1966 and August 2015. The databases were searched using the relevant $\mathrm{MeSH}$ terms including all subheadings: 'clinical decision-making', 'decision support techniques', 'decision support systems, clinical', 'decision-making, computer-assisted', 'decision trees', 'communication', 'informed consent', 'consent forms', 'reproductive medicine' and 'health education'. This was combined with a keyword search that included 'presentation of risk', 'public perception of risk', 'communication of risk', 'consent', 'decision-aid', 'counselling', and the search was limited to English language publications. The following websites were also searched using the abovementioned phrases: Bandolier, Medicines and Healthcare products Regulatory Agency, Royal College of Physicians, Royal College of Anaesthetists, Royal College of Surgeons, Royal College of Obstetricians and Gynaecologists, Department of Health, Medical Defence Union, National Institute for Health and Care Excellence, Scottish Intercollegiate Guidelines Network, National Screening Committee, World Health Organization, The Risk Information Institute, Kings Fund, Royal Society, Research Findings Register, The National Health and Medical Research Council of Australia, the International Patient Decision Aid Standards Collaboration, and The Institute of Risk Management. We included trials, qualitative studies, systematic reviews and reviews addressing decisionmaking, decision aids, counselling, risk presentation, communication or its public perception and consent, in relation to SRH.

\section{WHAT IS RISK?}

A risk is the likelihood (or probability) that harm will occur from a particular hazard. ${ }^{4}$ Patients may be concerned with broader qualitative attributes, such as the origin of the risk (natural or technological), whether a risk is imposed or temporary, and the power that they have to control the risk. ${ }^{5}$ Many times in reproductive healthcare there are hazards associated with a particular decision. For example, there are risks of pelvic inflammatory disease (PID) with an IUD, a probability of up to 9 in 100 of pregnancy with typical use of combined oral contraception, ${ }^{6}$ or a consequence that well over half of progestogen implant users experience a change in menstrual bleeding pattern. ${ }^{7}$ Patients will generally take risks if they perceive that there is an advantage or benefit. Normally, the benefits should outweigh the risks by a significant margin. There is no such thing as a zero risk ${ }^{8}$ and patients should be made aware that there is no medicine or drug without a possible risk or side effect, including medicines used for contraception.

Risk perception is subjective. ${ }^{10}$ Patients tend to act on the basis of their perception of the risk rather than the on 'actual' risk presented to them. ${ }^{11}$ Their estimates of risk may differ from those of the healthcare professional who counsels them. ${ }^{2} 1213$ Other factors may play a role. For example, uptake of genetic testing in prenatal care was strongly predicted by women's general attitude to genetic testing, independent of risk perception. ${ }^{14}$ Risks may be perceived as far less tolerable if the treatment or intervention is voluntary, the technology is unfamiliar or has no benefit for the patient.

\section{IMPORTANCE OF GOOD RISK COMMUNICATION}

Good communication helps to build trusting relationships between patients and professionals, leads to greater satisfaction on both sides, ${ }^{4}$ with less fear of treatments, ${ }^{15}$ helps people to take more responsibility for their own health, reduces medical errors and mishaps and even malpractice claims. ${ }^{10} 16$ Healthcare professionals tend to consider risk as the mathematical probability of something happening within a whole population group (e.g. the chance of an ectopic pregnancy in women using an IUD), which is supported by statistical information. ${ }^{1}$ This way of assessing risk is important, but it is objective, impersonal and deals with populations rather than individuals. Conversely, patients use an everyday concept of risk that is bound up in the individual's concerns, anxieties and fears about the present and the future (e.g. "What is my risk of having an ectopic pregnancy while using an IUD?"). Understanding the uncertainty about a treatment is thought to be a critical element of an informed decision and should be communicated effectively to patients. ${ }^{17} 18$ At the same time, the healthcare professional should make an assessment of the patient's mental capacity to understand the information given, considering this in the light of the Mental Capacity Act 2005. Healthcare professionals have traditionally communicated risk poorly, ${ }^{19}$ but developments such as patient decision aids can improve risk communication. ${ }^{20}$

\section{LEGAL ASPECTS OF RISK PERTAINING TO PATIENT CONSENT}

The legal position on whether or not a doctor or other healthcare professional is negligent in failing to mention a risk to a surgical patient was decided in the UK in the case of Sidaway. ${ }^{21}$ The more recent Montgomery v Lanarkshire Health Board judgment ${ }^{22}$ highlights the importance of an individual approach to advising a patient about a risk. When discussing the benefits and risks of various treatment options with patients, the new ruling requires doctors to consider whether "a reasonable person in the patient's position 
would be likely to attach significance to the risk, or the doctor is or should reasonably be aware that the particular patient would be likely to attach significance to it". ${ }^{22}$ Rather than a radical change in medical practice, the judgement has been considered to bring the law in line with current ethical guidance for UK doctors, as stated in the General Medical Council guidance on consent. ${ }^{23}$ It is therefore advisable to inform the patient of any 'material' or 'significant' risks of the proposed treatment, any alternatives to it, and the risks incurred by doing nothing. A Court of Appeal judgment stated that it will normally be the responsibility of the doctor to inform a patient of "a significant risk which would affect the judgment of a reasonable patient" [Pearce $\mathrm{v}$ United Bristol Healthcare NHS Trust (1998) 48 BMLR 118 (CA)]. ${ }^{24}$ It is appropriate to warn of a relatively rare risk for an elective procedure (e.g. pregnancy following laparoscopic sterilisation) if this might have a huge impact on the patient if it occurs.

\section{HOW TO COMMUNICATE RISKS}

Risks in SRH are personal and rich in uncertainty and there are no clear best practices for presenting information about uncertainty. ${ }^{17}$ Risk communication can be improved, however, by employing certain strategies as described below.

1. Personalised risk communication tailors information to an individual's risk status. For example, current evidence suggests a risk of weight gain with Depo-Provera ${ }^{\circledR}$ injection use compared to the oral contraception or no hormonal contraceptive method, and more so if the user is already overweight. This risk can be personalised, for example, by telling a woman with a body mass index of 32 that the average increase in weight over 18 months after starting Depo-Provera is $9.4 \mathrm{~kg}$ compared to $0.2 \mathrm{~kg}$ if she took oral contraception and $3.1 \mathrm{~kg}$ if she did not use hormonal contraception. ${ }^{25}$ Personalising risk communication enhances informed decision-making. ${ }^{26} \mathrm{~A}$ Cochrane Systematic Review found that for individuals undergoing screening procedures, interventions with a 'personalised risk communication element' enhance informed decision-making. ${ }^{26}$ Overall 45.2\% (592/1309) of participants who received personalised risk information made informed choices, compared to 20.2\% (229/ 1135 ) of participants who received generic risk information [odds ratio for random effects 3.65, 95\% confidence interval 2.13-6.23]. Personalised risk communication does not significantly increase the uptake of such screening tests.

2. Using a range of presentation styles and risk communication tools is the most effective way to give information about risks to patients. ${ }^{27} \mathrm{~A}$ randomised controlled trial of women's understanding of the effectiveness of contraceptive methods found that tables with categories such as 'more' or 'less effective' communicated relative effectiveness better than numeric tables. However, women grossly overestimated the risk of pregnancy unless they were shown tables with numbers, so a combination of both methods was best. ${ }^{28}$ Graphically presenting risk information in addition helped general practitioners to build a relationship with women, and allowed them to convey absolute and relative risks quickly without having to explain these concepts. ${ }^{29}$ A specifically designed tool, the Paling palette (Risk Communication Institute, http:// www.riskcomm.com/paling_palettes.htm) can display most medical risks with a probability of higher than 1 in 1000. The chart shows 1000 people, with the number experiencing a particular effect coloured in (Figure 1). An alternative system uses icon arrays (http://www. iconarray.com), a matrix of usually $100-1000$ icons to represent an at-risk population, simultaneously displaying both the number of expected events and the number of expected non-events.

3. Framing health information as negative or positive can affect patient understanding of risk. ${ }^{30}{ }^{31}$ As an example, comparing the chances of combined oral contraception failing in a good user $(<1$ in 100 , negative framing) versus the chances of successful contraception $(<99$ in 100 , positive framing). People receiving information framed as a positive or a gain have more confidence in a treatment than those receiving information presented as a negative or loss. Since framing of information can have such a profound effect on patient perception of risk, framing information in a variety of ways is recommended to avoid misunderstanding. ${ }^{32}$ For example, a patient may be told that there is a 1 in 10 chance that she will have a pregnancy in the first year of using a diaphragm, so this is a 9 in 10 chance that she will not conceive in the first year (typical risk of contraceptive failure with a diaphragm is $16 \%$ ).

4. The duration of the risk should also be discussed with the patient at the same time as discussing the amount of risk. ${ }^{33}$ For example, the risk of PID after IUD insertion among 22908 IUD insertions and during 51399 woman-years of follow-up was 1.6 cases per 1000 woman-years of use on average, but after adjustment for confounding factors, PID risk was more than six times higher during the 20 days after insertion than during later times (unadjusted rates, 9.7 vs 1.4 per 1000 woman-years, respectively); the risk was low and constant for up to 8 years of follow-up. ${ }^{34}$

\section{AIDING DECISION MAKING}

Decision aids such as pamphlets or videos prepare patients to participate in decisions by providing information about treatment or screening options and their associated outcomes. When compared with usual care, decision aids performed better in terms of greater knowledge, more realistic expectations, lower decisional conflict, and an increased proportion of people participating in decision-making. ${ }^{20}$ More detailed decision aids such as booklets or computer-based programmes are better than simpler ones and significantly improve knowledge, create more realistic expectations 
Effectiveness of Emergency Contraception

1000 women have a single episode of UPSI

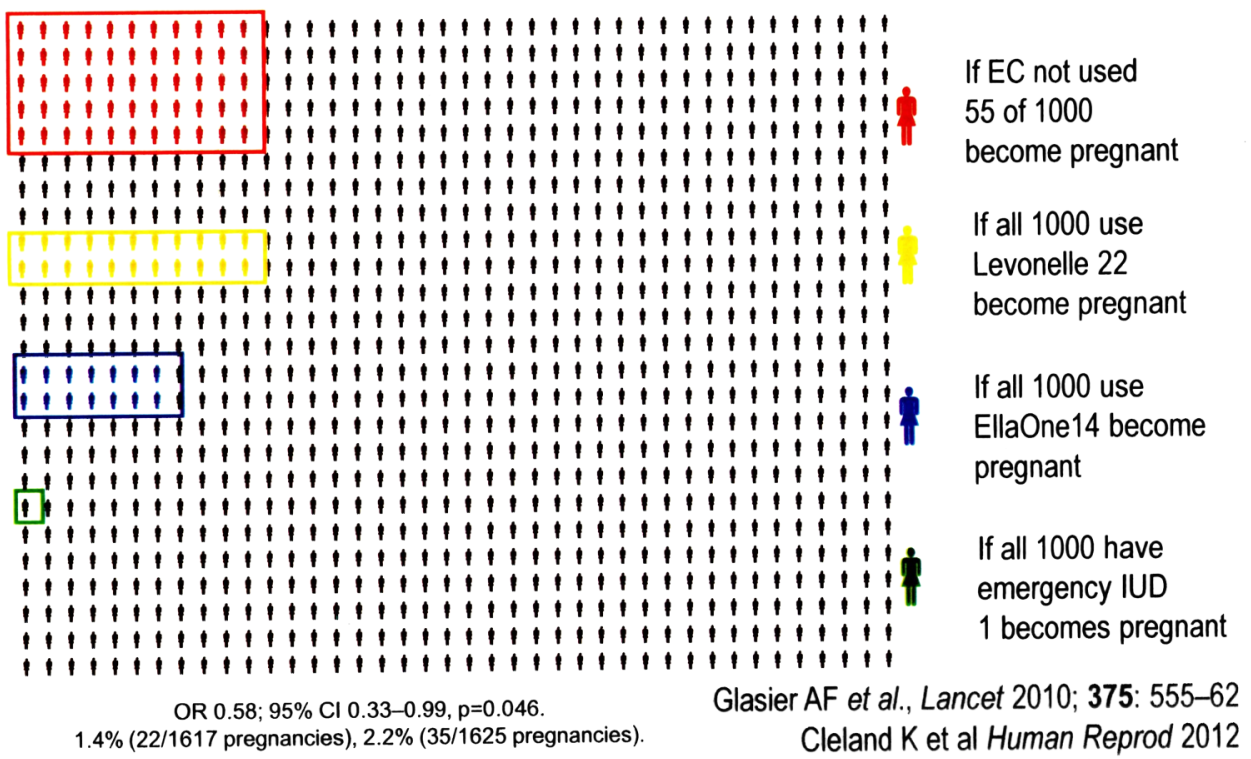

Figure 1 A graphic display to compare the effectiveness of different types of emergency contraception (developed using data from references 56, 57). CI, confidence interval; EC, emergency contraception; IUD, intrauterine device; OR, odds ratio; UPSI, unprotected sexual intercourse.

and greater agreement between values and choice. A decision aid for choosing pregnancy termination methods, for example, improved knowledge and reduced risk-perception scores about both methods compared to usual counselling methods. ${ }^{35}$ In general, structured, tailored and/or interactive communication tools are more effective at increasing a patient's understanding of evidence. ${ }^{36}$ For contraceptive methods, a recent systematic review found that a range of educational interventions can increase knowledge. ${ }^{37}$ Further research is needed, however, to determine what aspects of educational interventions are most effective, whether an educator is needed, and how education may impact behaviours.

\section{PRESENTING NUMERICAL RISK INFORMATION FOR PATIENTS}

The format in which written and verbal information on probability is presented affects patient understanding of risk. Patients have a more accurate perception of risk if the information is presented as numbers rather than words. ${ }^{36}$ Presenting natural frequencies, which is a joint frequency of two events, such as the number of patients with a disease and who have a positive test result, ${ }^{38}$ may also be beneficial.

A change in risk is better understood if absolute risk reduction, or a relative risk reduction with the baseline risk format for the disease, is used. ${ }^{36}$ For example, there is up to a $30 \%$ (30 in 100) chance of pregnancy when a woman has unprotected sex during her fertile period. Typical failure of condoms to prevent pregnancy is $10-15 \% \quad(10-15$ per 100 women). By using the IUD for emergency contraception this risk of pregnancy is reduced to $<1 \%(<1$ in 100 women will get pregnant). The absolute pregnancy risk reduction is $29 \%$ with IUD use, greater than with condom use. Further worked examples for calculating risk reduction are available. ${ }^{39}$ Descriptive terms such as 'very low risk' or 'high risk' may be used, but they should be qualified by giving a figure, such as a frequency, since they can reflect the speaker's perspective and not the patient's view. ${ }^{40}$

European Union (EU) guidelines recommend verbal descriptors of risk. ${ }^{9}$ From a regulatory perspective for patient information leaflets, the emphasis is to express risk as a statistical probability, for example, a verbal descriptor such as 'very rare' corresponds to 'up to $0.01 \%$ ' $(<1 / 10000)$. However, research into what individuals understand by terms such as 'very rare' or 'common' suggests that the current EU guidelines on verbal descriptors are not correctly matched with statistical probabilities. ${ }^{41}{ }^{42}$ The public equate the verbal descriptors (very rare, common, and so on) to risks that are substantially higher than those defined in regulatory documents. The current EU guidelines are provided in Table $1 .^{9}$

Percentages are an abstract way of portraying risk (e.g. 5\%), whereas the actual number of people who could be affected is more vivid to some patients (e.g. 5 in every 100 people). Consequently, when quantifying risks it is recommended to use frequencies rather than percentages to portray risk, ${ }^{41}$ and to help compare between risks, use a consistent denominator. ${ }^{42}$ Example 1 below uses a consistent 
Table 1 Risk table (modified from reference ${ }^{55}$ )

\begin{tabular}{lll}
\hline $\begin{array}{l}\text { Verbal } \\
\text { description* }\end{array}$ & Risk & Risk descriptiont \\
\hline Very common & $1 / 1$ to $1 / 10$ & A person in a family \\
Common & $1 / 10$ to $1 / 100$ & A person in a street \\
Uncommon & $1 / 100$ to $1 / 1000$ & A person in a village \\
Rare & $1 / 1000$ to $1 / 10000$ & A person in a small town \\
Very rare & $<1 / 10000$ & A person in a large town \\
\hline
\end{tabular}

*European Union assigned frequency.

tUnit in which one adverse event would be expected.

denominator to compare venous thromboembolism (VTE) risks. Another example using a constant denominator considers contraceptive efficacy, stating that in 1 year of use, 99/100 women will not get pregnant with an IUD, whereas only 85/100 women will not get pregnant with typical use of a male condom.

Using relative risks alone to compare different options can be misleading ${ }^{41}$ as was demonstrated in the 1995 'pill scare'. Epidemiologists reported that use of third-generation oral contraceptives doubled the risk of VTE compared with use of secondgeneration oral contraceptives. ${ }^{43}$ The initial reports did not mention that the absolute risks were low: $1 / 3000$ compared with $1 / 6000$, that the background risk in non-users was $1 / 20000$, or that the increased risk of death was around 1/1000 000. The risk was not put into context and media and public panic ensued. ${ }^{44}$ Evidence suggests that presenting the risk of thrombosis complications in terms of incidence rather than relative risk may improve communication of side effects during counselling for combined hormonal contraception initiation. ${ }^{45}$

Over the last decade there has, however, been little improvement in the reporting of absolute risks. ${ }^{46}$ For many observational studies and meta-analyses, absolute risks cannot be reported easily or meaningfully. Wherever possible absolute risks should be stated, since using absolute data allows the consumer to more easily compare different risks. ${ }^{41}$

Examples of communicating risks in SRH are provided below.

Example 1: A woman asks you what her risk is of having VTE while using the combined pill

The risk of VTE (deep venous thrombosis and pulmonary embolism) in women who are not using the combined contraceptive pill is $2-5 / 10000$ womanyears. ${ }^{47}$ This means that in 10000 women not using the pill over a 1-year period up to five may have VTE (hence it is 'rare'). This doubles to 5-12/10 000 woman-years, which is still rare to uncommon, in women who are using combined hormonal contraception. ${ }^{48} 49$ In pregnancy and the immediate postpartum, the risk of VTE is much higher: 29/10 000 woman-years and over 10 times higher postpartum$300-400 / 10000$ woman-years. VTE is therefore rare in women who use the combined pill. Women are at a
Table 2 Risk of venous thromboembolism associated with non-use, combined hormonal contraception use over the course of 1 year $^{56}$

\begin{tabular}{ll}
\hline Scenario & $\begin{array}{l}\text { Risk of VTE per 10 000 } \\
\text { healthy women }\end{array}$ \\
\hline $\begin{array}{l}\text { Non-contraceptive users and not pregnant } \\
\text { CHC containing ethinylestradiol plus }\end{array}$ & 2 \\
levonorgestrel, norgestimate or norethisterone & $5-7$ \\
$\begin{array}{l}\text { CHC containing etonogestrel (ring) and } \\
\text { norelgestromin (patch) }\end{array}$ & $6-12$ \\
$\begin{array}{l}\text { CHC containing ethinylestradiol plus } \\
\text { gestodene, desogestrel, drospirenone }\end{array}$ & $9-12$ \\
$\begin{array}{l}\text { Pregnancy } \\
\text { Immediately postpartum }\end{array}$ & 29 \\
\hline
\end{tabular}

CHC, combined hormonal contraception; VTE, venous thromboembolism.

far greater risk of VTE postpartum or during pregnancy than while taking the combined pill as shown in Table 2.

Example 2: A woman is interested in having intrauterine contraception but has heard IUDs are associated with pelvic infection. She asks what her risk is of having a pelvic infection if she chooses an IUD.

The risk of a pelvic infection while using intrauterine contraception is generally low, ${ }^{50}$ but is increased where there is a sexually transmitted infection (STI) and in the first 3 weeks after IUD insertion. The most comprehensive review to date of insertions and IUD use suggests a risk of up to $16 / 10000$ woman-years, ${ }^{34}$ hence pelvic infection after IUD insertion or with IUD use is uncommon. Also, pelvic infection has not been found to be higher in women using IUDs compared to women who are using other methods of contraception such as progestogen-only injectables ${ }^{51}$ or no contraception. ${ }^{52}$ By preventing STIs, the risk of pelvic infection with IUD is further reduced. The patient should be offered an STI screen before her IUD insertion and should practise safer sex to reduce her risk of pelvic infection with the IUD. ${ }^{53}$

Example 3: You offer a woman with postcoital bleeding a chlamydia test but she declines. Her last STI screen, 6 months ago, was negative and she has not changed partner since. Her partner has never been screened for STIs before, but she believes he has no infection as her own results have been negative. What will your advice be?

The woman's own negative test results may suggest, but cannot guarantee, that her partner does not have an infection. Most currently used STI test kits have a sensitivity and specificity of over $97 \%$, so the test will miss 3 in 100 (or 1 in 30) infections. The efficiency of a test depends on the test's ability to give a positive result when there is an infection (sensitivity) and its ability to give a negative result when there is no infection (specificity). Contaminants and hormonal factors may affect a test result; hence no test is $100 \%$ accurate. ${ }^{54}$ It is therefore good practice to repeat some tests 
when indicated, even if the patient may have done the test previously. This patient has postcoital bleeding and a chlamydia test is clinically indicated. You would therefore recommend a repeat chlamydia test, and an STI screen for her partner.

\section{CONCLUSIONS}

Presenting information about risk in a way that facilitates patient understanding improves decision-making and patient satisfaction with care. Presenting risk in a personalised way, using decision aids or interactive methods, presenting information in a variety of formats, and framing the risk in both a negative and a positive way all improve risk communication. Patients have a more accurate perception of risk if information on probability is described in numbers rather than words. Most people understand natural frequencies or event rates better than probability formats with varying denominators.

Acknowledgements The authors wish to thank Dr Jayne Kavanagh for her helpful advice during the writing of this article.

Funding Anna David receives funding at UCLH/UCL via the Department of Health's NIHR Biomedical Research Centres funding scheme.

Competing interests None declared.

Provenance and peer review Commissioned; externally peer reviewed.

\section{REFERENCES}

1 Herxheimer A. Communicating with patients about harms and risks. PLoS Med 2005;2:e42.

2 Lloyd A, Hayes P, Bell PR, et al. The role of risk and benefit perception in informed consent for surgery. Med Decis Making 2001;21:141-149.

3 Royal College of Obstetricians and Gynaecologists. Presenting Information on Risk (Clinical Governance Advice No. 7). Royal College of Obstetricians and Gynaecologists, 2008.

4 Lloyd AJ. The extent of patients' understanding of the risk of treatments. Qual Health Care 2001;10(Suppl. 1):i14-i18.

5 Calman KC. Cancer: science and society and the communication of risk. BMJ 1996;313:799-802.

6 Trussell J. Contraceptive failure in the United States. Contraception 2011;83:397-404.

7 Mansour D, Korver T, Marintcheva-Petrova M, et al. The effects of Implanon on menstrual bleeding patterns. Eur J Contracept Reprod Health Care 2008;13(Suppl. 1):13-28.

8 Fischhoff B, Slovic P, Lichtenstein S, et al. How safe is safe enough? A psychometric study of attitudes towards technological risks and benefits. Policy Sci 1978;9:127-152.

9 Slovic P. Perception of risk. Science 1987;236:280-285.

10 Levinson W, Roter DL, Mullooly JP, et al. Physician-patient communication. The relationship with malpractice claims among primary care physicians and surgeons. JAMA 1997;277:553-559.

11 Brewer NT, Chapman GB, Gibbons FX, et al. Meta-analysis of the relationship between risk perception and health behavior: the example of vaccination. Health Psychol 2007;26:136-145.
12 Ellis DA, Hopkin JM, Leitch AG, et al. "Doctors' Orders": controlled trial of supplementary, written information for patients. Br Med J 1979;1:456.

13 US National Research Council. Improving Risk Communication: Report of the Committee on Risk Perception and Communication. 1989. The National Academies Press, Washington DC, USA ISBN: 978-0-309-08669-1. doi:10.17226/1189

14 Barnoy S, Zelikaman L, Bar-Tal Y. To take or not to take genetic carrier tests: personal characteristics associated with taking recommended and nonrecommended tests. Genet Test Mol Biomarkers 2009;13:453-458.

15 Stewart MA. Effective physician-patient communication and health outcomes: a review. Can Med Assoc J 1995;152:1423-1433.

16 Gordon-Lubitz RJ. Risk communication: problems of presentation. JAMA 2003;289:10-11.

17 Politi MC, Han PKJ, Col NF. Communicating the uncertainty of harms and benefits of medical interventions. Med Decis Making 2007;27:681-695.

18 Volk RJ, Llewellyn-Thomas H, Stacey D, et al. Ten years of the International Patient Decision Aid Standards Collaboration: evolution of the core dimensions for assessing the quality of patient decision aids. BMC Med Inform Decis Mak 2013;13 (Suppl. 2):S1.

19 Braddock CH III, Edwards KA, Hasenberg NM, et al. Informed decision making in outpatient practice. JAMA 1999;282:2313-2320.

20 O'Connor A, Bennett C, Stacey D, et al. Decision aids for people facing health treatment or screening decisions. Cochrane Database Syst Rev 2009;3:CD001431.

21 Wells WT. The Sidaway case. Lancet 1985;1:709.

22 United Kingdom Supreme Court. Montgomery v Lanarkshire Health Board UKSC 11. The Supreme Court, 2015.

23 General Medical Council. Consent: Patients and Doctors Making Decisions Together. General Medical Council, Manchester UK, 2009.

24 Dennehy L, White S. Consent, assent, and the importance of risk stratification. Br J Anaesth 2012;109:40-46.

25 Bonny AE, Ziegler J, Harvey R, et al. Weight gain in obese and nonobese adolescent girls initiating depot medroxyprogesterone, oral contraceptive pills, or no hormonal contraceptive method. Arch Pediatr Adolesc Med 2006;160:40-45.

26 Edwards AGK, Naik G, Ahmed H, et al. Personalised risk communication for informed decision making about taking screening tests. Cochrane Database Syst Rev 2013;2: CD001865.

27 Edwards A, Elwyn G, Gwyn R. General practice registrar responses to the use of different risk communication tools in simulated consultations: a focus group study. BMJ 1999;319:749-752.

28 Steiner MJ, Dalebout S, Condon S, et al. Understanding risk: a randomized controlled trial of communicating contraceptive effectiveness. Obstet Gynecol 2003;102:709-717.

29 Edwards A, Elwyn G, Mulley A. Explaining risks: turning numerical data into meaningful pictures. BMJ 2002;324:827-830.

30 Paling J. Strategies to help patients understand risks. BMJ 2003;327;745-748.

31 Malenka DJ, Baron JA, Johansen S, et al. The framing effect of relative and absolute risk. J Gen Intern Med 1993;8: 543-548.

32 O'Doherty K, Suthers GK. Risky communication: pitfalls in counseling about risk, and how to avoid them. J Genet Couns 2007;16:409-417. 
33 Committee on Safety of Medicines Working Group on Patient Information. Always Read the Leaflet. Getting the Best Information with Every Medicine. The Stationery Office, 2005.

34 Farley TM, Rosenberg MJ, Rowe PJ, et al. Intrauterine devices and pelvic inflammatory disease: an international perspective. Lancet 1992;339:785-788.

35 Wong SSM, Thornton JG, Gbolade B, et al. A randomised controlled trial of a decision-aid leaflet to facilitate women's choice between pregnancy termination methods. BJOG 2006;113:688-694.

36 Trevena LJ, Davey HM, Barratt A, et al. A systematic review on communicating with patients about evidence. J Eval Clin Pract 2006;12:13-23.

37 Pazol K, Zapata LB, Tregear SJ, et al. Impact of contraceptive education on contraceptive knowledge and decision making: a systematic review. Am J Prev Med 2015;49(Suppl. 1):S46-S56.

38 Gigerenzer G. What are natural frequencies? BMJ 2011;343: d6386.

39 Barratt A, Wyer PC, Hatala R, et al. Tips for learners of evidence-based medicine: 1 . Relative risk reduction, absolute risk reduction and number needed to treat. CMAJ 2004;171:353-358.

40 Merz JF, Druzdzel MJ, Mazur DJ. Verbal expressions of probability in informed consent litigation. Med Decis Making 1991;11:273-281.

41 Australian Government National Health and Medical Research Council. Making Decisions About Tests and Treatments: Principles for Better Communication between Healthcare Consumers and Healthcare Professionals. NHMRC Publications, Australia, 2005.

42 Grimes DA, Snively GR. Patients' understanding of medical risks: implications for genetic counseling. Obstet Gynecol 1999;93:910-914.

43 Wood R, Botting B, Dunnell K. Trends in conceptions before and after the 1995 pill scare. Popul Trends 1997;89:5-12.

44 Mills A. Avoiding problems in clinical practice after the pill scare. Hum Reprod Update 1999;5:639-653.

45 Machado RB, Morimoto M, Santana N, et al. Effect of information on the perception of users and prospective users of combined oral contraceptives regarding the risk of venous thromboembolism. Gynecol Endocrinol 2015;31(1):57-60.

46 Schwartz LM, Woloshin S, Dvorin EL, et al. Ratio measures in leading medical journals: structured review of accessibility of underlying absolute risks. BMJ 2006;333:1248.

47 European Medicines Agency. Benefits of Combined Hormonal Contraceptives (CHCs) Continue to Outweigh Risks - CHMP Endorses PRAC Recommendation. 2013.

48 Hannaford PC. Epidemiology of the contraceptive pill and venous thromboembolism. Thromb Res 2011;127(Suppl. 3): S30-S34.

49 Reid R, Leyland N, Wolfman W, et al. SOGC clinical practice guidelines: Oral contraceptives and the risk of venous thromboembolism: an update: no. 252, December 2010. Int J Gynaecol Obstet 2011;112:252-256.

50 O'Brien PA, Marfleet C. Frameless versus classical intrauterine device for contraception. Cochrane Database Syst Rev 2005;1: CD003282.

51 Hofmeyr GJ, Singata M, Lawrie TA. Copper containing intra-uterine devices versus depot progestogens for contraception. Cochrane Database Syst Rev 2010;6:CD007043.

52 Paladine HL, Blenning CE, Judkins DZ, et al. Clinical inquiries. What are contraindications to IUDs? J Fam Pract 2006;55:726-729.

53 Faculty of Sexual \& Reproductive Healthcare Clinical Effectiveness Unit. Intrauterine Contraception. The Faculty of Sexual and Reproductive Healthcare, UK, 2007.

54 British Association for Sexual Health and HIV. Chlamydia Trachomatis UK Testing Guidelines. 2006. British Association for Sexual Health and HIV.

55 Calman KC, Royston GH. Risk language and dialects. BMJ 1997;315:939-942.

56 Faculty of Sexual \& Reproductive Healthcare. The FSRH Statement in Response to the Combined Pill Communication from the Medicines and Healthcare Products Regulatory Agency (MHRA). The Faculty of Sexual and Reproductive Healthcare, UK, 2014.

\section{READERS' CONTRIBUTIONS INVITED ON 'A BETTER WAY OF WORKING'}

The Journal publishes occasional 'A Better Way of Working' articles, the purpose of which is to disseminate service delivery suggestions likely to be of interest and relevance to the Journal's readership. Readers are invited to submit suggestions based on their own personal experience for consideration by the Journal Editor. Contributions normally should not exceed 1000 words and should be written in a standardised format responding to the following four questions (or similar): Why was change needed? How did you go about implementing change? What advice would you give to others who might be considering a similar course of action? How did you show that the change had occurred? All contributions should be submitted via the Journal's online submission system at http://mc.manuscriptcentral.com/jfprhc. 